\title{
GRAFIAS DO GESTO NA DANÇA: NOTAS ESPARSAS
}

\author{
Marcílio Souza Vieira \\ Professor nos Programa de Pós-Graduação em Artes Cênicas, Pós-Graduação no Ensino das Artes e \\ no Curso de Graduação em Dança da Universidade Federal do Rio Grande do Norte \\ Pós-Doutor em Artes pela UNESP e Doutor em Educação pela FRN \\ Email: marciliov26@hotmail.com
}

Resumo

A necessidade de criação de uma escrita para a dança se refere à função de registro e conservação das obras do repertório da dança e a grafar o essencial de uma criação coreográfica, sem apresentar as interpretações pessoais de cada bailarino, como ocorre quando se aprende uma coreografia olhando alguém dançando. Na história da dança, várias notações existiram e sucumbiram. Mas algumas permaneceram por algum tempo e tem sua relevância histórica. Destaca-se a escrita de Beauchamp-Feuillet, que foi a escrita desenvolvida para o ballet francês de corte. Há ainda que se destacar a escrita de Stepanov que até hoje de algum modo serve ao Ballet Russo. Destaca-se ainda a Beneshnotation, a Sutton Movement Writing \& Shorthand e a Labanotation (termo usado nos Estados Unidos) ou Kinetografia (termo usado na Europa) que sem sombra de dúvida inaugurou outra história nas grafias do movimento. O presente trabalho tem como objetivo apresentar e descrever as grafias de notação do gesto na dança. Fundamenta-se na fenomenologia como abordagem metodológica; para a produção de dados de pesquisa será utilizada a técnica da descrição dos fenômenos. A descrição busca a "própria coisa", e, embora enraizada, encontra-se repleta de significados vividos dia a dia, "sem que isso seja conscientizado ou verbalizado".

Palavras-chave

Dança. Gesto. Notação Coreográfica.
Abstract

The need to create a writing for dance refers to the function of recording and preserving the works of the dance repertoire and to grappling the essential of a choreographic creation, without presenting the personal interpretations of each dancer, as it happens when learning a choreography Looking at someone dancing. In the history of dance, various notations existed and succumbed. But some have remained for some time and have their history relevance. Noteworthy is the writing of Beauchamp-Feuillet, which was the writing developed for the French ballet of court. We must also highlight the writing of Stepanov that to this day somehow serves the Russian Ballet. Beneshnotation, the Sutton Movement Writing \& Shorthand, and Labanotation (the term used in the United States) or Kinetography (a term used in Europe), which undoubtedly inaugurated another story in the spellings of the movement, are also noteworthy. The present work aims to present and describe the gesture notation spellings in dance. It is based on phenomenology as a methodological approach; for the production of research data will be used the technique of describing the phenomena. The description seeks the "own thing", and although rooted, is full of meanings lived day by day, "without this being aware or verbalized."

Keywords

Dance. Gesture. Choreographic Notation. 
Os gestos fazem parte dos meios usados para o ser humano se comunicar; contribuem para dar forma e codificar as relações sociais entre os indivíduos e entre os grupos. Schmitt (2006) afirma serem os gestos constituintes de uma realidade social e que dependem da história social. São o meio pelo qual o corpo estabelece relações simbólicas enquanto apreensão individual, interpessoal e de movimento.

A historicidade do corpo faz com que haja modificações, e nossos gestos adquiram significados novos mediante as experiências que vão ocorrendo. É através desses gestos que somos capazes de expressar muitos desses símbolos e esconder outros, formando, portanto, a linguagem do corpo que está sempre se reorganizando. E por possuir espacialidade e temporalidade próprias, cada corpo vai adquirindo percepções de acordo com o mundo que lhe é específico.

Os gestos enfatizam, descrevem, completam; às vezes traem o conteúdo de um discurso oral. Estão sempre presentes na performancedo bailarino-intérprete. Na dança, quando os bailarinos-intérpretes dançam, comunicam-se, usam o gesto como linguagem. Eles demonstram comportamentos constituídos a partir de sequências de movimentos e gestos. Assim, cativam, tomam, capturam as pessoas e se comunicam através do gesto que não ocorre linearmente somente a partir do interlocutor, porque o sentido do gesto não é dado, é compreendido e retomado por um ato do espectador.

Na Fenomenologia da Percepção Merleau-Ponty (1999) concebe a relação entre repertório gestual e linguagem que entendemos como as vozes do silêncio quando o bailarino-intérprete se utiliza de seu vocabulário gestual para mostrar seus movimentos dançados. Esse si- lêncio, como apontou Nóbrega (2016), a partir da leitura de Merleau-Ponty, é o silêncio dos gestos, com sua imensa capacidade de criar sentidos, de significar e de, como diz Merleau-Ponty (1991, p. 59) "[...] admitir uma verdade que não se assemelhe às coisas, que não tenha modelo exterior, nem instrumentos de expressão predestinados, e que seja, contudo, verdade".

Assim, obtém-se a comunicação ou a compreensão dos gestos pela reciprocidade entre minhas intenções e os gestos do outro, entre meus gestos e intenções legíveis na conduta do outro. Tudo se passa como se a intenção do outro habitasse meu corpo ou como se minhas intenções habitassem o seu. (Merleau-Ponty, 1999, p. 251)

O gesto, na dança, é o comentarista da palavra, é a revelação do pensamento da dança desses bailarinos-intérpretes. Ele é poético, pois este bailarino-intérpretedança consigo, dança com o outro, faz sua dança, incorpora gestualidades extra cotidiana, de seu mundo vivido, gestualidades apreendidas por uma determinada técnica de dança, e essas gestualidades são incorporadas em suas vivências quando dança.

Os gestos se revelam num poder persuasivo, colocando em jogo todos os sentidos, não só de quem executa, mas também de quem observa. Merleau-Ponty (1999) afirma que o corpo é o nosso meio geral de ter o mundo. Para o filósofo, esse corpo, quando se movimenta, reorganiza-se, informa-se sobre o meio ambiente, ao mesmo tempo informa-se sobre si mesmo, criando significações transcendentes ao dispositivo anatômico. Desse modo, o autor citado argumenta que: 
Ora ele se limita aos gestos necessários à conservação da vida e correlativamente, põe em torno de nós um mundo biológico; ora, brincando com seus primeiros gestos e passando de seu sentido próprio a um sentido figurado, ele manifesta através dele um novo núcleo de significação: é o caso dos hábitos motores como a dança. Ora, enfim, a significação visada não pode ser alcançada pelos meios naturais do corpo; é preciso então que ele se construa um instrumento, e ele projeta em torno de si um mundo cultural. (Merleau-Ponty, 1999, p. 203)

Na dança, o gesto é singular a cada bailarino-intérprete; esses gestos criam sentidos de significações quando se tornam dança, quando saem de sua utilidade técnica cotidiana e ganham outras expressividades no movimento dançado, logo, ao criarem sentidos, eles admitem verdades ou uma verdade. Parafraseando Merleau-Ponty sobre essa verdade, no que concerne ao gesto dançado, embora o filosofo não tenha tematizado a dança em seus escritos, "Uma verdade que não se assemelhe às coisas, que não tenha modelo exterior nem instrumentos de expressão predestinados, e que seja, contudo, verdade". (Merleau-Ponty, 1999, p. 59)

$O$ referido autor argumenta que,

É por meu corpo que compreendo o outro, assim como é por meu corpo que percebo coisas. Assim compreendido, o sentido do gesto não está atrás dele, ele se confunde com a estrutura do mundo que o gesto desenha e que por minha conta eu retomo, ele se expõe no próprio gesto. (Merleau-Ponty, 1999, p. 253)

Na dança, a amplitude, o ritmo, a velocidade desses movimentos e dessas ações gestuais têm a maior importância: um gesto pode ser apressado, mas também pode ser, depen- dendo das circunstâncias, lento, comedido, exacerbado ou mesmo condensar-se à realidade a que se adequa seu bailarino-intérprete. Na dança, toda gestualidadeé elemento de grande impacto na transmissão e recepção da performance do bailarino-intérprete. Neste, os movimentos acompanham a narração da cena e, como justifica Zumthor (2010, p.207), “[...] cabe ao corpo modalizar o discurso, explicar seu intento. O gesto gera no espaço a forma externa do poema. Ele funda sua unidade temporal, escandindo-a de suas recorrências".

O presente trabalho tem como objetivo apresentar e descrever as grafias de notação do gesto na dança. Fundamenta-se na fenomenologia como abordagem metodológica; para a produção de dados de pesquisa será utilizada a técnica da descrição dos fenômenos. A descrição busca a "própria coisa", e, embora enraizada, encontra-se repleta de significados vividos dia a dia, "sem que isso seja conscientizado ou verbalizado".

\section{Notações de dança}

Dança é tracejar, tocar, desenhar vértices e linhas do cubo, icosaedro e octaedro. Mas, por outro lado, principalmente no estudo dos esforços, Laban parece entender que os esforços são encorpados através de certa experiência cotidiana e revelam a história e a cultura deste corpo, aqui passamos de uma visão metafísica a uma existência social, histórica e cultural do corpo e do gesto, logo imanente.

A reflexão labaniana coaduna, certa maneira, com o pensamento merleaupontyano sobre o corpo e o gesto. Ser corpo, como diz o filósofo fenomenólogo, é estar atado a um certo mundo e "[...] nosso corpo não está 
primeiramente no espaço: ele é no espaço". (Merleau-Ponty, 1999, p. 205) Tal espacialidade reverbera no gesto que por sua vez pode ser"notado" na dança a exemplo da escrita Beauchamp-Feuillet, Stepanov, Beneshnotation, Sutton Movement Writing \& Shorthand e Labanotation.

O movimento e o gesto quando "notado" participam, ao meu ver, daquilo que Merleau-Ponty (2004) chamou de as vozes do silêncio, posto que sendo linguagem não diz pela fala, mas diz a seu modo pelo corpo: eis o movimento e o gesto dançados. Mas, o que é essa linguagem que não diz (fala)? Para o filósofo citado, a pintura, para a dança, o movimento e o gesto. De antemão, parafraseando Merleau-Ponty, o gesto celebra o enigma da visibilidade. Ele se vê em seu mover-se, ele é vidente. "[...] Ele não está na ignorância de si, não é cego para si, irradia de um si" (Merleau-Ponty, 2004, p.27).

Aqui, a notação em dança, para se fazer, tem necessidade do lugar, do onde, que ela deve não imitar, não estar presa às referências visíveis, perspectivas e objetivas do onde, mas que deve, ao ser dançada, que o corpo do intérprete ao ler tal notação possa expressar a escrita valendo-se de suas experiências corporais e dançantes.

A necessidade de criação de uma escrita para a dança se refere à função de registro e conservação das obras do repertório da dança e a grafar o essencial de uma criação coreográfica, sem apresentar as interpretações pessoais de cada bailarino, como ocorre quando se aprende uma coreografia olhando alguém dançando. (Preston-Dunlop, 1969; Guest, 1998)

$\mathrm{Na}$ história da dança, várias notações existiram e sucumbiram. Mas algumas permaneceram por algum tempo e tem sua relevância histórica. Destaca-se a escrita de Beauchamp-Feuillet, que foi a escrita desenvolvida para o ballet francês de corte. Há ainda que se destacar a escrita de Stepanov que até hoje de algum modo serve ao Ballet Russo. Destacam-se ainda a Beneshnotation, a Sutton Movement Writing \& Shorthand e a Labanotation (termo usado nos Estados Unidos) ou Kinetografia (termo usado na Europa) que sem sombra de dúvida inaugurou outra história nas grafias do movimento.

Nas partituras de Beauchamp-Feuillet, os desenhos geométricos sobre o solo são altamente visíveis. Sabe-se também que o ballet é uma dança da hipervalorização da destreza de membros inferiores, logo a grafia se concentra em vários detalhes de membros inferiores. Somente quando é necessário, essas partituras pontuam alguma condução de braços; não organizadas pela sintaxe do ballet é que os braços são grafados. Tais características podem ser visualizadas na figura $n^{\circ} 01$ uma partitura para balé barroco. Nela é possível observar o plano de um palco com sua geometria espacial.

Figura 1: Notação Beauchamp-Feuilletpara balé barroco.

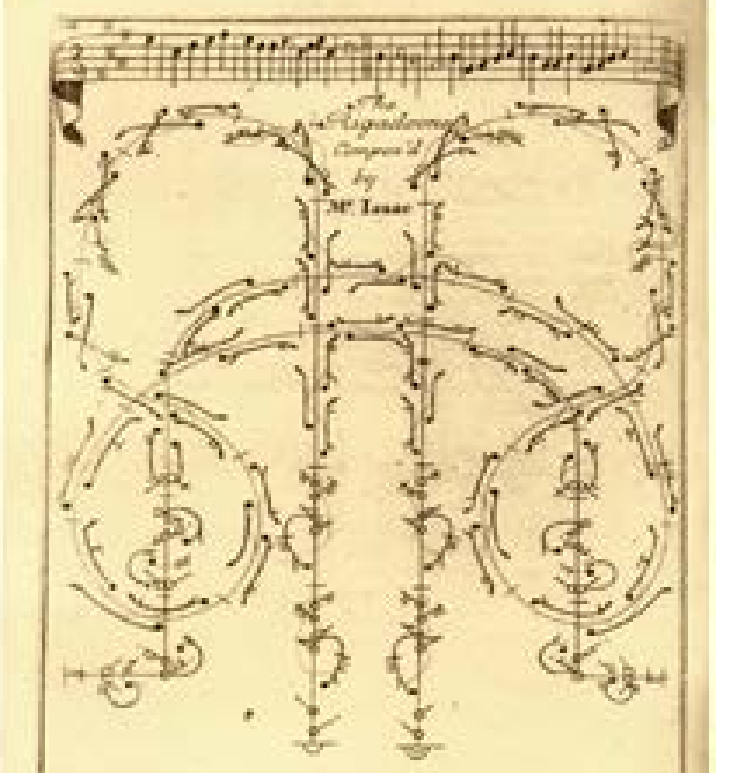

Fonte: CK Dexter Haven.

Vieira // Grafias do Gesto na Dança: notas esparsas Rev. Cena, Porto Alegre, n. 22, p. 75-86, jul./out. 2017 Disponível em: http://seer.ufrgs.br/cena 
Feuillet registrou as posições iniciais dos pés e seu desenho no solo. Os signos para demonstrar saltos e passos registravam os pés, o tronco e os braços, enfatizando o deslocamento em todo o espaço do palco. Nessa forma de grafar o corpo na dança,distinguem-se quatro eixos perpendiculares para a execução do movimento, a saber: frontal, dorsal, lateral e girando.

A escrita da dança do método Stepanov baseou-se em notas anatômicas do corpo que se complementavam com as notas musicais. Esse método é um alfabeto dos movimentos do corpo humano codificados pelos movimentos da dança com notas musicais e não com símbolos abstratos. Tais movimentos eram registrados como sinais musicais.

Cabe registrar que essas duas formas de grafar o movimento e os gestos humanos foram propostas e executadas nos séculos XVII e XVIII. Em nossa leitura sobre os métodos Feuillet e Stepanov não observamos nas notações uma proposição da "fisionomia do gesto" (Merleau-Ponty, 1999) que aponta para a cena um modo performático substituindo o modo narrativo muito comum nos balés daquela época.

Registra-se que os coreógrafos da época foram influenciados pela lógica cartesiana. Vale citar como exemplo desse período a noção de perspectiva ${ }^{1}$. Necessário se faz uma crítica a esse modelo de perspectiva sob o olhar fenomenológico de Merleau-Ponty, posto que os coreógrafos notadores daquela época se utilizavam de tal perspectiva para suas escritas de dança e para o movimento e o gesto dançados. É preciso dizer que a grande desenvoltura

1 Não vamos nos deter na filosofia cartesiana para entendimento dessas notações de dança, no entanto, faz-se necessário comentar o pensamento merleaupontyano acerca da noção de perspectiva. dessas notações de dança, em especial para ballet, era visualizada pela capacidade de os coreógrafos atuarem como os geômetras cartesianos.

Ao criticar a noção da perspectiva renascentista, Merleau-Ponty (2004), de certa maneira, critica a Dioptrica de Descartes e exemplifica essa noção a partir da visão. Longe de retratar a realidade objetiva, a visão é um filtro altamente seletivo e a imagem por ela capturada, enganosa.

A visão, para o filósofo supracitado, tem função perceptiva e cognitiva, pois possibilita saber das coisas no espaço, e até tomar ciência do próprio corpo, tendo como escopo o visível. A visão recebe ecos e os acolhe, mas é a partir do corpo que percebemos, expressamos, existimos, criamos, de maneira inédita, particular. É a partir do corpo que se deflagra todo o processo de ser no mundo, do corpo "nosso ancoradouro no mundo", e não há possibilidade de usurpação da significação de outro.

Como diz Merleau-Ponty (2004) é através do olhar que primeiro interrogamos as coisas, e devemos compreender o corpo, de forma geral, como um sistema voltado para a inspeção do mundo. Trata-se, pois, de entender a visão originária, esquecida nas atividades cotidianas, já que é comum à percepção e à fala se esquecerem em benefício do sentido da coisa ou do significado conquistados.

$\mathrm{Na}$ primeira metade do século $\mathrm{XX}$ foram criadas outras formas de escrita da dança tais como a Beneshnotation, a Sutton Movement Writing \& Shorthand e a Labanotation.

$\mathrm{Na}$ Benesh e na Sutton, a lógica do frame é evidente. Viu-se que a lógica do balé é a lógica do instante privilegiado. Assim não é destacado o fluxo do movimento, mas as poses são 
consideradas momentos de extrema importância para a técnica e poética do balé. Logo, ambas as notações grafam destacando as poses, mais do que o movimento.

Os dois métodos utilizam-se do pentagrama como base da notação coreográfica, como se o bailarino fosse um instrumento musical.

A Beneshnotation representa graficamente o corpo do bailarino (a), conforme pode ser observado na notação da figura $n^{\circ} 2$, dentro de uma pauta de cinco linhas, passando pelo topo da cabeça, pelos ombros, pela cintura, pelos joelhos e pelo nível do chão. Nessa pauta anota-se com sinais e traços a posição e o movimento da cabeça, dos braços, das mãos, das pernas e dos pés do bailarino. A partir de três sinais surge todo o método: horizontal, vertical e uma bolinha (Guest, 1998).

Figura 2: Notação Beneshnotation.

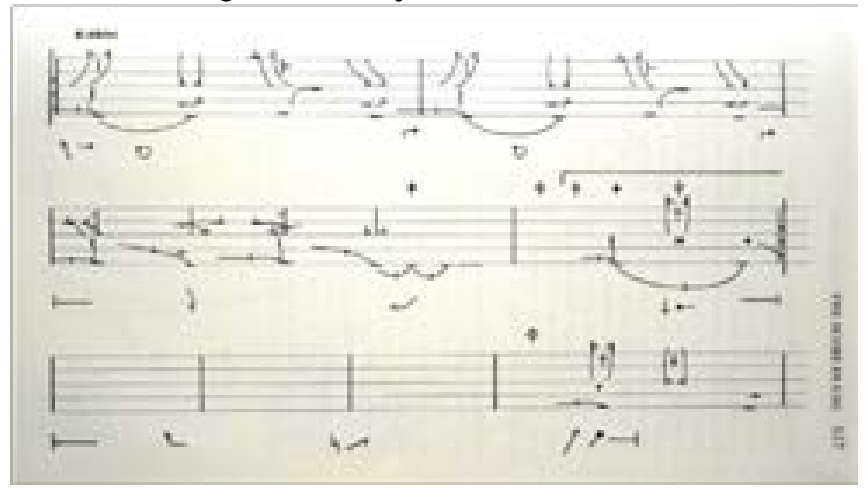

Fonte: Margo Halverson.

Cabe registrar que, como aponta Guest (1998), a notação é escrita em um formulário de cinco linhas que é lida da esquerda para a direita e do alto para baixo da página.

A Sutton Movement Writing \& Shorthand é uma forma de grafar o movimento aplicada ao ballet. O sistema inclui cinco seções a Dance Writing, a Sign Writing, a Mime Writing, a Sports Writing e a Science Writing respectivamente para a grafia do movimento registrando as coreografias, registrando a língua de sinais, registrando a mimica e a pantomime clássica, registrando o movimento esportivo e registrando os movimentos de animais, linguagem corporal, dentre outros (Sutton, 2004).

A Labanotation, seguindo a classificação geral de Ann Hutchinson Guest (1998) é uma grafia feita por símbolos abstratos e não são as posições que são evidentes em sim um entremear dos gestos dos diversos seguimentos corporais em diferentes temporalidades próprias, uma espécie de contraponto corporal, tendo uma relação muito mais com o fluxo do que a lógica dos frames.

A Labanotation iniciou no século $X X$ sendo hoje uma das grafias de movimento mais conhecida. Ao criar a Labanotation, Laban criou um sistema filosófico, no qual o gesto humano é o próprio elemento constitutivo do homem. Um conceito encarnando no sentido merleau-pontyano.

Em seus estudos sobre a Labanotation Almeida (2012) diz que essa escrita de dança não é apenas uma grafia rígida e precisa dos movimentos, mas é a grafia das forças, a grafia das unidades de energias dos gestos e, isto é, a condição de possibilidade para o pensamento labaniano monadológico e filosófico. Laban, de acordo com seus biógrafos, provavelmente não deva ter estudado a obra de Leibniz, mas parece que ambos, dentro de suas áreas de estudos, se aproximaram em diversos pontos, em especial no que concerne à teoria dos Esforços produzida pelo artista húngaro. O que Leibniz concebeu ontologicamente, Laban parece ter empregado em suas pesquisas práticas sobre o corpo, como se fosse um eco do primeiro.

Pode-se pensar numa aproximação entre Leibniz e Laban ao intuir que os Esforços são energias puras do movimento, diferentes entre 
si e unidades indivisíveis, e como as mônodas, os Esforços se agrupam produzindo todos os gestos que existem. (Almeida, 2012)

Almeida (2012, p. 166) diz que Laban, semeIhante a Leibniz, também apresentava críticas à maneira reducionista cartesiana de se estudar o movimento humano. "Foi no cotidiano, no corpo em ação, nos homens das ruas, realizando trabalhos, afazeres, andando, jogando, dançando, que ele buscou o entendimento do movimento".

Criticando a forma científica tradicional de observar o movimento, Laban (1990, p. 49) afirma que:

[...] as explicações racionalistas insistem no fato de que os movimentos do corpo humano estão submetidos às leis do movimento inanimado. O peso do corpo segue a lei da gravidade. $O$ esqueleto do corpo pode ser comparado a um sistema de alavancas que faz com que se alcancem, no espaço, as distâncias e se sigam as direções. Estas alavancas são acionadas pelos nervos e músculos que providenciam a força necessária para superarmos o peso das partes do corpo que se movem. A fluência do movimento é controlada por centros nervosos que reagem aos estímulos internos e externos. Os movimentos se processam durante algum tempo, e podem ser medidos com exatidão. A força propulsora do movimento é a energia desenvolvida por um processo de combustão no interior dos órgãos corporais. O combustível consumido neste processo é o alimento. Não resta dúvida quanto ao aspecto puramente físico da produção de energia e de sua transformação em movimento.

A grafia de dança construída pelo artista húngaro é similar a uma notação musical que se usa uma pauta. Consiste em três linhas dispostas verticalmente e a contagem é lida de baixo para cima. Laban cria para sua partitura um trigrama (três linhas paralelas para serem escritas na vertical). O trigrama, para Laban
(1992; 2001) é síntese extremamente simplificada do corpo humano.

O trigrama de Laban apresenta um linha central que indica o eixo axial do corpo, os dois espaços internos delimitados pelas duas outras linhas paralelas indicam os membro inferiores, para fora destas linhas estão os membros superiores, o tronco, a cabeça. Observa-se que Laban (2011) para chegar ao seu trigrama provavelmente partiu da figura do corpo humano contida no pentágono por ele apresentado para apresentar a Kinesfera.

No trigrama os símbolos $(D, \square, \square, \square$, ) são escritos para indicar em que sentido a parte específica do corpo deve se mover. $\mathrm{O}$ comprimento do símbolo mostra o período de tempo de tomadas do movimento, do seu início a sua extremidade. Para indicar que sentido ocorre o movimento são usados símbolos básicos que indicam tal sentido de movimento e estes sinais são modificados por três tipos de sombreados ( $\ell$, , []) que indicam a dimensão vertical no trigrama. (Guest, 1998)

Para Laban o gesto é constituído por unidades pré-gestuais. A natureza do gesto assim seria uma natureza de forças, de potências puras. Se de algum modo entende-se uma ontologia em Laban que relaciona a gênese do gesto a fatores sociais, culturais e históricos, não se pode deixar de anunciar que em diversos momentos a gênese do gesto em Laban é evidentemente metafísica, isto é, o gesto dá visibilidade a estruturas, a formas, a forças universais, trazidas para a terra pelo corpo do bailarino em movimento. O gesto, comenta Almeida (2012), já não precisa ser extraordinário, acrobático e extra cotidiano como ocorre no balé, mas na simplicidade do gesto cotidiano há uma poética intensa. Logo, a intensidade do gesto não está na sua monumentalidade, 
mas no sentido existencial que ele carrega, na sua força poética expressiva.

Essa força poética expressiva é no nosso entendimento o que Merleau-Ponty (1999) chama de modo de apreensão sensível na base da compreensão da fala e do gesto corporal. Apreende-se o significado da palavra assim como apreende-se o sentido de um gesto: "[...] eu não percebo a cólera ou a ameaça como um fato psíquico escondido atrás do gesto, leio a cólera no gesto, o gesto não me faz pensar na cólera, ele é a própria cólera". (Merleau-Ponty, 1999, p. 251). Isto não quer dizer, porém, que o filósofo simplifique a análise do gesto, reduzindo sua compreensão a um imediatismo da percepção, como se os gestos fossem objetivamente dados na experiência do sujeito. Ele diz:

Todavia, o sentido do gesto não é percebido do mesmo modo que, por exemplo, a cor do tapete. Se ele me fosse dado como uma coisa, não se vê por que minha compreensão dos gestos se limitaria, na maior parte das vezes, aos gestos humanos. (idem)

Merleau-Ponty, por sua vez, recorre à expressão emocional dos gestos para encontrar aí os primeiros indícios da linguagem como um fenômeno autêntico, mas evitando o risco do reducionismo como ocorre na concepção naturalista, pois tanto a fala como o gesto são fenômenos específicos e contingentes em relação a organização corporal. Ou seja, "[...] aproximando a linguagem das expressões emocionais, não se compromete aquilo que ela tem de específico, se é verdade que já a emoção [...] é contingente em relação aos dispositivos mecânicos contidos em nosso corpo [...]". (Ibidem, p. 256)

Os gestos, portanto, não são oferecidos deliberadamente ao espectador como uma coisa a ser assimilada; eles são retomados por um ato de compreensão, cujo fundamento nos remete à situação em que os sujeitos da comunicação - eu e o outro - estão mutuamente envolvidos em uma relação de troca de intenções e gestos. Em outros termos:

O sentido dos gestos não é dado, mas compreendido, quer dizer, retomado por um ato do espectador. Toda dificuldade é conceber bem esse ato e não confundi-lo com uma operação do conhecimento. Obtém-se a comunicação ou a compreensão dos gestos pela reciprocidade entre minhas intenções e os gestos do outro, entre meus gestos e intenções legíveis na conduta do outro. Tudo se passa como se a intenção do outro habitasse meu corpo ou como se minhas intenções habitassem o seu. (Merleau-Ponty, 1999, p. 251)

Dessa forma, podemos fazer uma aproximação do pensamento merleaupontyano sobre o gesto com a gestologia em Laban, que segundo o artista húngaro essa se constrói silenciosamente nas histórias significativas das experiências corporais que produzem diversos gestos com suas dinâmicas (esforços) e espacialidades. Parece que para estudar o corpo, Laban preferiu observar a complexidade do movimento humano em suas ações cotidianas, admirou o movimento dos homens no trabaIho, nas ruas e indústrias, nas inúmeras danças campestres, teatrais e de salões, percebeu o comportamento motor do burguês e do operário e ficou perplexo mais uma vez com a capacidade variacional do movimento humano e com os múltiplos significados e ações que este pode produzir.

A Labanotation (vide figura 3) foi a condição de possibilidade para ser criar outra ordem de pensamento sobre o movimento. Nesta direção Laban afirma (Laban apud Maletic, 1987) 
que a partitura, representado as leis imanentes do gesto, seria uma base para uma nova ordem de composição em dança. Essa escrita foi produzida ao longo da obra do coreógrafo e pesquisador de dança húngaro e para cada pesquisa o artista buscava os signos para representar seus parâmetros de movimento. Sua estruturação e evolução contou com a participação de vários colaboradores como Ann Hutchinson Guest (1998).

Figura 3: Partitura em Labanotation (Staff).

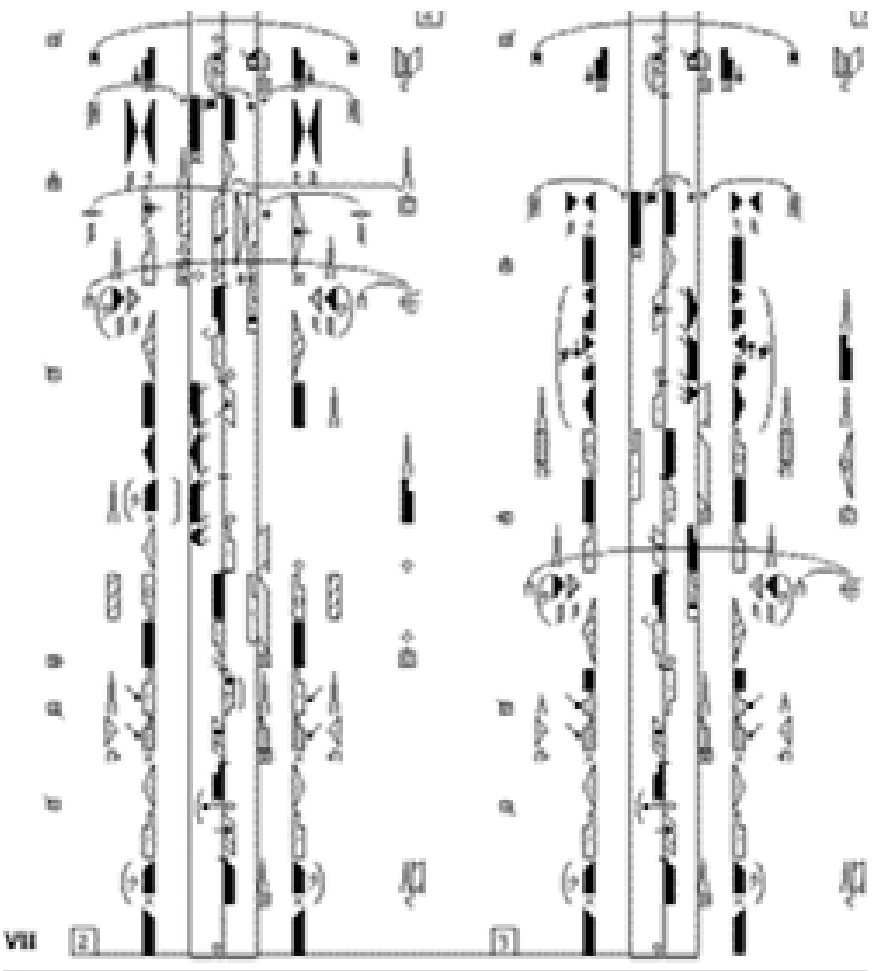

Fonte:Les carnets bagouet.

A lógica da Labanotation é a lógica das forças e segue a mesma direção por sua necessidade extremada de síntese e de redução. Laban afirmava (Laban apud Maletic, 1987, p.114) que "o escopo da notação da dança deve incluir a representação de leis imanentes do movimento".

Há uma questão técnica importante ao pensar a notação, pois a possibilidade gestual do corpo é infinita e se Laban procurasse grafar cada gesto necessitaria ter um vocabulário de signos gigantesco que impossibilitaria a memória e uso racional da Labanotation. Cada traço nessa grafia é um fragmento de um símbolo complexo, que apenas tem sua forma final por lógica combinatória. Um ângulo agudo ou uma ponta nela pode voltar-se para esquerda ou para direita, para cima ou para baixo, indicando a direção do movimento. Mas este ângulo ou ponta pode estar presente em diversos símbolos.

Tal possibilidade incomensurável do gestual do corpo se revela como um espaço expressivo, com capacidade para desenvolver totalidades que nenhuma de nossas partes pode esgotar, restaurando-se assim, o valor ontológico da nossa experiência corporal com o mundo que se dá pela experiência do corpo consigo mesmo pela percepção, sensação e ação. As coisas e o outro são percebidas pelo nosso corpo, o qual as acolhe assim como as suas ações e gestos, que desenham um sentido para mim.

Ao acreditar que o movimento humano seguiria padrões específicos e universais, Rudolf Laban passou a crer ser possível criar uma forma de notação que dessa conta de descrever com precisão os movimentos do corpo. Sua escrita de movimentos, conhecida como Labanotation, divide o corpo em partes e associa um símbolo a cada uma delas.

Ao criar essa grafia de movimento Laban possibilitou refletir outra ordem de pensamento sobre o movimento, uma nova ordem de composição em dança. A criação de tal sistema de notação comporta um rico material didático-pedagógico para a teorização e exploração das possibilidades expressivas do movimento humano (Eucinética) e suas possíveis organizações espaciais (Corêutica).

Para grafar os movimentos Laban criou uma 
vasta simbologia que posta dentro ou fora do trigrama representam os gestos que o corpo é capaz de fazê-lo ao dançar.

A forma simbólica utilizada é o retângulo que, colocado na pauta do trigrama fornece quatro elementos básicos que reproduzem o movimento. Esses elementos são segundo Guest (2004) a direção, o nível, o tempo/duração e a parte do corpo que se move. A direção indica como o movimento ocorre no espaço e é representado pela forma geométrica triangular que recortado apresenta outras possibilidades de direção. Os símbolos de direção são baseados em três sólidos espaciais, a saber: octaedro com uma única direção de movimento (eixo), icosaedro com duas direções de movimento (diametral) e o cubo com três direções de movimento (diagonal).

Figura 4: representação de um Trigrama.

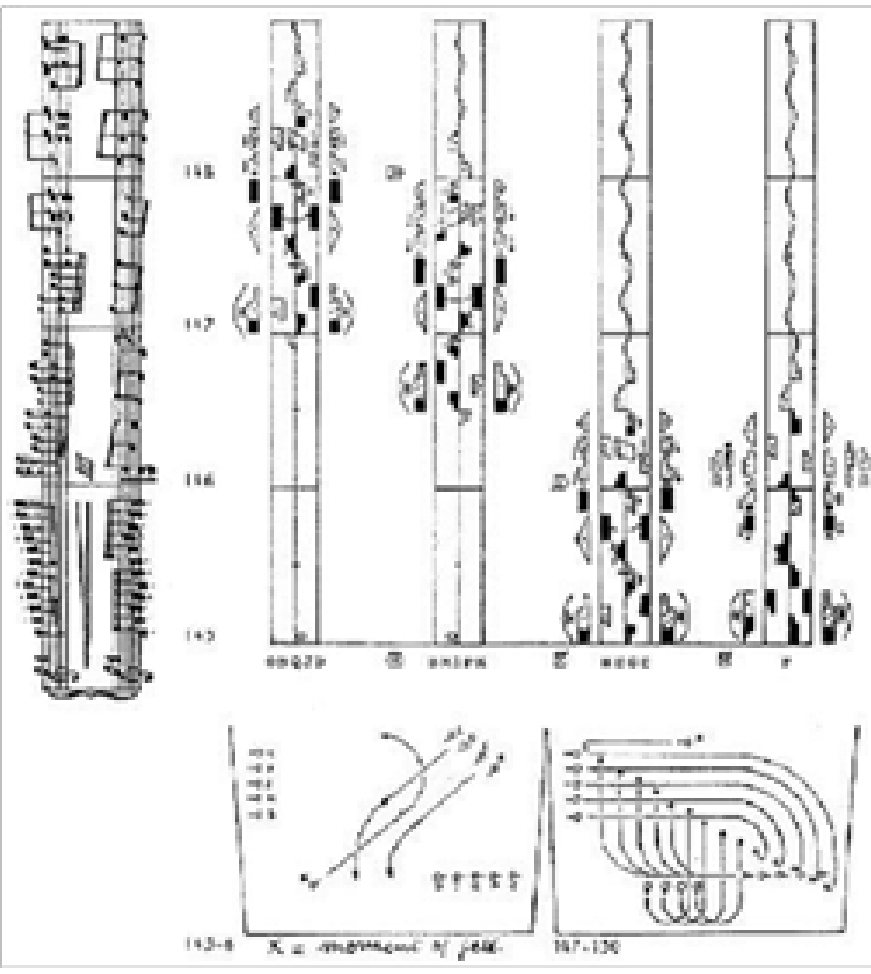

Fonte: GUEST, Ann Hutchinson. Choreo-graphics, 1988.

O nível indica se o movimento é realizado em baixo, no meio ou em cima. Quando o símbolo vem cortado por traços indica um movimento para o alto, quando ele é chuleado (todo pintado) indica que o movimento está sendo feito para o nível baixo e quando ele vem com um ponto no centro do símbolo indica movimento no meio. O tempo é metrificado como na música ou qualquer outra unidade temporal. $\mathrm{Na}$ Labanotation o tamanho do símbolo indica a ação do movimento, é sua plasticidade icônica que indica a duração do movimento. O outro elemento - parte do corpo que se move é indicado no trigrama onde é colocado o símbolo, em qual coluna do trigrama, conforme figuras $n^{\circ} 4$. Convém ressaltar que qualquer parte do corpo pode virar suporte (quando o símbolo toca a coluna do trigrama), qualquer parte pode virar gesto (quando o símbolo não toca a coluna).

Dada a relevância dos símbolos na Labanotation, faz-se necessário pontuar que todo símbolo que toca a linha média do trigrama é chamado de suporte de membros inferiores, ou seja, é aquele que sustenta o peso do corpo e os que não toca essa linha é denominado de gesto.

Acentua-se ainda que o trigama usado na Labanotation é uma partitura (Staff) que se lê de baixo para cima. O Staff é representado por três linhas principais e demais linhas secundárias que representam gestos de pernas e suportes direito e esquerdo, tronco, braços mãos e cabeça. Ele representa o corpo humano. Com essa grafia para dança Laban criou uma monumentalidade para a dança, criou, dessa maneira, uma nova ordem de pensamento, outra lógica de criação coreográfica e uma nova forma de análise do movimento.

Almeida (2012) clarifica que na Labanotation há uma questão técnica importante ao pensar a notação, pois a possibilidade gestual do corpo é infinita e se Laban procurasse grafar cada 
gesto necessitaria ter um vocabulário de signos gigantescos que impossibilitaria a memória e uso racional de sua notação.

Para minimizar essa exacerbação de símbolos, Laban, a partir do retângulo dá a base para a criação de outros símbolos norteadores de sua Labanotation. A representação gráfica do triângulo, por exemplo, colocada a direita ou à esquerda do trigrama indica um movimento em direção ao meio. O retângulo no formato de " $L$ " indica movimento para frente (quando a ponta do L está para cima) e para baixo (quando a ponta do L está para baixo); já o trapézio irregular pode indicar movimentos para a direita ou esquerda alta e/ou direita e esquerda baixa dependendo de seu posicionamento no trigrama.

Guest (2004) explica que para termos a noção de que parte do corpo se move, estes símbolos devem ser colocados dentro (membros inferiores) ou fora (membros superiores) do trigrama. "[...] Somente na relação das lógicas dos símbolos é que o movimento começa a se concretizar, símbolos, ou traços de símbolos apenas apresentam forças, potências do gesto". (Almeida, 2012, p.190)

Laban ao apresentar seu método de notação propôs uma escrita de movimento que possibilitou ao intérprete-criador executar uma obra coreográfica com padrões de movimentos exatos como criados pelo coreógrafo para tal obra. Assim como dois músicos que residem em diferentes localidades do planeta conseguem ler e executar uma peça musical a partir da leitura da mesma partitura, dois intérpretes-criadores poderiam executar a mesma obra baseados em uma mesma partitura de movimento. De fato, Laban criou um método próprio propiciando a escrita do movimento através de códigos. Para tanto, como exem- plificado em parágrafos anteriores criou um dicionário para que o intérprete-criador pudesse executar os movimentos sem intermédio ou orientação de um coreógrafo. Ele se esforçou para a construção de uma notação que em muito poderia ajudar a dança em complexas criações coreográficas.

\section{Considerações finais}

Para compreender a Labanotation é preciso entender a lógica dos pré-símbolos e suas relações combinatórias, isto é, a lógica de combinação presente na obra de Laban tem sua dinâmica mais radical na sua notação para a dança.

Ao se refletir sobre as grafias de dança percebeu-se que a Labanotation parece ser a que mais se utiliza para se pensar uma escrita para dança. Embora as demais grafias tivessem tido sua importância, Laban elaborou uma grafia que deu conta de pensar a dança como escrita. Ele criou assim uma grafia para a dança que no Ocidente pode ser visitada por quaisquer intérpretes criador que domine tal escritura.

Necessário se faz refletir que, embora na contemporaneidade se tenha a web e em tempos remotos a fita $K 7$, o vídeo, as notações servem para que o intérprete criador que saiba ler as notações possam transmitir para seu corpo o que os notadores quiseram dizer com suas notações para determinada obra sem que recaiam na cópia ou repetição de movimentos e gestos por ventura aprendidos pela via da imitação, comum quando se aprende uma determinada coreografia a partir de artefatos como o vídeo, por exemplo.

Acredito que, das grafias do gesto comentadas nesse artigo, a Labanotation certamente 
se adequa a qualquer corpo dançante, desde que o intérprete saiba lê-la, interpretá-la.

Referências

ALMEIDA, Marcus Vinicius Machado de. Laban e o corpo intenso. Relatório de Pós-Doutorado em Psicologia, Universidade Federal Fluminense, 211 p. 2012 . São Paulo, UFF, 2012.

GUEST, Ann Hutchinson. Choreo-graphics: a comparison of dance notation systems from the fifteenth century to the present. Netherlands: Gordon and Breach Publishers, 1988.

Labanotation: the system of analyzing and recording movement. New York and London: Routledge, 2004.

LABAN, Rudolf. The mastery of movement. London: Northcote House, 1992.

. Una vida para la danza. Mexico: Conaculta, 2001.

A vision of dynamics space. London: The Falmer Press, 1984.

.Choreutics. London; Dance Books, 2011.

NÓBREGA, Terezinha Pretucia. Corporeidades: inspirações merlou-pontianas. Natal: IFRN, 2016.

MALETIC, Vera. Body, space, expression.. Berlin: Moutande Gruyter, 1987.
MERLEAU-PONTY, Maurice. Fenomenologia da percepção. Tradução de Carlos Alberto Ribeiro de Moura. 2 ed. São Paulo: Martins Fontes, 1999.

O olho e o espirito. São Paulo: Cosac \& Naify, 2004.

PRESTON-DUNLOP. Pratical Kinetography Laban. London: MacDonald \& Evans, 1969.

SUTTON, Valerie. O centro para a escrita do movimento de Sutton: Dancing Writing. Califórnia, 2004. Disponível em: www.MovementWriting.org. acessado em 20 de março de 2013.

ZUMTHOR, Paul. Introdução à poesia oral. Tradução de Jerusa Pires Ferreira. São Paulo: Hucitec, 2010.

Recebido: 08/04/2017 Aprovado: 08/06/2017 